\title{
Perceptions of body image among working men and women
}

\author{
C Emslie, K Hunt, S Macintyre
}

The British Government has expressed concern about media images that equate female beauty with extreme thinness. In 2000 the Minister for Women, Tessa Jowell, held a series of meetings with representatives from modelling agencies and teenage magazines to discuss possible links between the use of thin models in the fashion industry, and mental health and eating disorders among girls and women.

Given that lay definitions of overweight may be different from medical definitions, ${ }^{1}$ it is important to explore whether people's perceptions of their weight differ from "objective" measurements such as body mass index (BMI). A concern with thinness is often seen as a woman only problem. Is this true?

\section{Methods and Results}

Postal questionnaires were sent to employees working full time within a British bank in clerical, supervisory and management jobs and to full time clerical, technical and academic employees in a British university. The response rate was $76 \%(n=2176)$ for the bank and $67 \%$ $(n=1641)$ for the university. Respondents were asked to report their height and weight so that body mass index $\left(\mathrm{kg} / \mathrm{m}^{2}\right)$ could be calculated. They were also asked to indicate whether they thought they were "about the right weight", "too heavy" or "too light" for their height. Self esteem was measured using the Rosenberg self esteem scale. ${ }^{2}$ Pregnant women were excluded from the analyses. Full data were available for 1070 men and 995 women in the bank and 964 men and 571 women in the university. Further details are published elsewhere. ${ }^{34}$

Accepted for publication 11 December 2000
Over one third of men $39.4 \%$ in the bank and $34.5 \%$ in the university) were "overweight" (defined as a BMI of 25 or more by the WHO Expert Committee on Overweight 1995) compared with $20.7 \%$ and $29.1 \%$ of women in the bank and university respectively. After controlling for age and occupational grade, men in the bank were significantly more likely to be overweight than women, but there was no significant gender difference in the university (table 1). However, women in both organisations were significantly more likely than men to perceive themselves as being "too heavy" for their height, even after controlling for body mass index, self esteem, occupational grade and age. In the university, women were more than three times more likely than men to think they were too heavy, while in the bank, women were 10 times more likely than men to perceive this. In both organisations, there was a significant interaction between gender and BMI. Men and women were similarly unlikely to think they were "too heavy" if their BMI was very low, and similarly likely if it was very high; however among those whose weight was "normal" (BMI 18.5-24.9) and those who were "mildly overweight" (BMI 25.0-29.9), women were more likely than men to think they were too heavy (data not shown).

\section{Discussion}

Among these respondents in full time work, women were significantly more likely than men to regard themselves as too heavy for their height. The magnitude of the gender difference is striking in both organisations. While gender differences have been found in other studies, ${ }^{15}$ they have not controlled for socioeconomic status. In contrast, our study compares men and women working full time in similar non-manual jobs within the same organisation.

As this study focused on non-manual employees, the results cannot be generalised to manual workers. We also used self reported measures of height and weight. There is some evidence $^{15}$ that women under report their weight more than men. However, underestimating women's BMI is unlikely to explain the large gender differences in body image found in both organisations.

Our findings suggest that concern about women's perceptions of their body image is well founded. Health promotion messages that focus on the dangers of being overweight may be particularly counterproductive for women who are already an appropriate weight for their height. 
We would like to thank the personnel departments in both organisations. This work would not have been possible without the participation of the bank and university employees who took the time and effort to complete the questionnaires. We would also like to thank Geoff Der for statistical advice and Lindsay Macaulay, Pat Fisher and Margaret Reilly for clerical assistance.

Funding: this work was funded via an MRC studentship to Carol Emslie. The authors are all employed by the UK Medical Research Council.

Conflicts of interest: none.
1 Crawford D, Campbell K. Lay definitions of ideal weight Crawford D, Campbell K. Lay definitions of
and overweight. Int f Obesity 1999;23:738-45.

2 Rosenberg M. Society and the adolescent self image. Princeton NJ: Princeton University Press, 1965.

3 Emslie C, Hunt K, Macintyre S. Problematizing gender, work and health: the relationship between gender, occupational grade, working conditions and minor morbidity in full-time bank employees. Soc Sci Med 1999;48:33-48.

4 Emslie C, Hunt K, Macintyre S. Gender differences in minor morbidity amongst full-time employees of a British University. $\mathcal{F}$ Epidemiol Community Health 1999;53:465-75.

5 Ziebland S, Thorogood M, Fuller A, et al. Desire for the body normal: body image and discrepancies between self-reported and measured height and weight in a British population. F Epidemiol Community Health 1996;50:105-6.

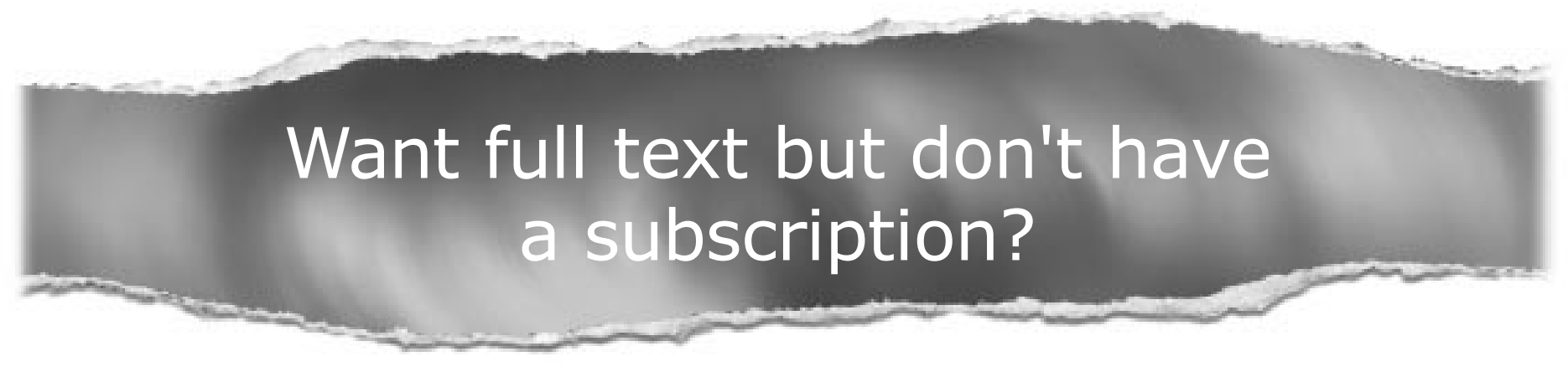

\section{Pay per view}

For just $\$ 8$ you can purchase the full text of individual articles using our secure online ordering service. You will have access to the full text of the relevant article for 48 hours during which time you may download and print the pdf file for personal use.

www.jech.com 